\title{
Identifying appropriate flagship species: the importance of culture and local contexts
}

\author{
Evan Bowen-Jones and Abigail Entwistle
}

\begin{abstract}
Over the last 50 years there has been increasing use of charismatic large mammals and birds as 'flagship species' to raise funds and promote the ethos of conservation. However, species chosen to appeal to donor and membership groups may not necessarily be considered popular among local communities. A growing recognition of the need to engage local communities in conservation makes them an increasingly important audience for information about conservation. In such situations an awareness of the local perception and value of different species is central to choosing effective flagships. Emphasising this, we propose 10 criteria for the
\end{abstract}

selection of flagship species. We then describe three examples of local flagship species and assess their use against these criteria: the Asian elephant Elephas maximus for the conservation of landscapes in Aceh, Indonesia, the flying fox Pteropus voeltzkowi for forest protection on Pemba Island, Tanzania, and the ceiba or kapok tree Ceiba pentandra for the conservation of forests in Belize.

Keywords Asian elephant, Ceiba pentandra, culture, flagship species, local communities, local participation, Pemba flying fox.

\section{Introduction}

The use of particular species or taxa as symbols or 'flagships' has been adopted by a wide range of organisations and agencies as a means of engaging and informing selected audiences about conservation efforts (Dietz et al., 1994). Species such as the giant panda Aluropoda melanoleuca, the tiger Panthera tigris and the African elephant Loxodonta africana have been used to promote the conservation imperative to audiences that include the general public, donors and political institutions. However, the participation of local communities in conservation has become increasingly important (BorriniFeyerabend, 1997), and we therefore question what role 'flagship species' have in relation to these communities, and how the most locally acceptable and useful symbols for conservation may be identified.

There have been several recent re-examinations of the definition of flagship species (Caro \& O'Doherty, 1999; Leader-Williams \& Dublin, 2000). For the purposes of this paper we regard them as "popular, charismatic species that serve as symbols and rallying points to stimulate conservation awareness and action" (Heywood, 1995). In general the most commonly used flagship species are ones that are internationally recognizable,

Evan Bowen-Jones (Corresponding author) and Abigail Entwistle Fauna \& Flora International, Great Eastern House, Tenison Road, Cambridge, CB1 2TT, UK. E-mail: evan.bowen-jones@fauna-flora.org and

abigail.entwistle@fauna-flora.org

Received 10 July 2001. Revision requested 21 November 2001. Accepted 5 December 2001 but it has been questioned whether the use of such species is effective in protecting other species or ecosystems with which they are associated (Entwistle \& Dunstone, 2000).

One of the greatest challenges to conservation is developing community-led projects that convey an awareness of benefits throughout the focal community, be they economic returns (Werner, 1991; Hutton \& Dickson, 2000) or reinforcement of inherent cultural associations or religious beliefs (Posey \& OCEES, 1999). In this context flagship species can illustrate the ecological and economic values of conservation. The flagships are likely to be relatively more effective if their selection takes into account local perceptions and attitudes, and if the species have links to the protection of cultural symbols and, ultimately, cultural identity.

There can be fundamental differences in peoples' perceptions of the value of particular species. A study in which schoolchildren in both Britain and Tanzania were asked to name their favourite animals showed that Tanzanians living close to protected areas held negative associations for the very species preferred by children in the UK (Entwistle \& Stephenson, 2000). British children appeared to prefer traditional flagship species, such as tiger, lion Panthera leo, and primates, which are generally foreign and have characteristics such as athleticism and ferocity. In contrast Tanzanian schoolchildren feared carnivores (lions and leopard Panthera pardus), and considered them a nuisance. These children cited their favourite mammals as zebra Equus zebra, giraffe Giraffa camelopardalis and buffalo Syncerus caffer on the basis of factors including attractiveness, meat quality and 
revenue generation; the children also liked elephants, despite some fear of them, due to their role in generating income from tourism. Thus, one cannot assume that all communities have the same perception of a given species.

Furthermore, there can be conflicts between the needs of local people and those of some recognized flagship species (including elephants, Sukumar, 1989, and tigers, Nowell \& Jackson, 1996). For example, although there is an international perception that tigers need to be protected (Dietz et al., 1994; Carvell, 1998), focusing on a potentially dangerous species can appear illogical to local stakeholders, and may lead to antagonism towards conservation agencies. One solution has been to attempt to change local attitudes to such potentially dangerous species. This has been successful in some cases, such as the use of great white sharks Carcharodon carcharias as a focus for marine tourism and conservation activities (Knights et al., 2000).

Another approach is to link conservation initiatives to species with existing local value, by the use of flagships that reflect a community's values of the natural world. In such situations careful participatory research avoids basing programmes on assumptions about local perceptions of species' values. The participation of communities in identifying a symbol for conservation can ensure that the flagship will be effective and will have emotional resonance and ownership among the local communities. The challenge lies in identifying species that appeal at both local and international levels.

Analysis of the use of flagship species has indicated that their general characteristics include appropriate geographical location, relevant ecological attributes, and the potential for building public support, including appearance and behaviour, visibility and cultural or religious significance (Dietz et al., 1994). In this paper we build on these characteristics, outlining 10 explicit criteria that should be considered when evaluating the potential for the use of flagship species at a local level. We describe three case studies of projects where this approach was adopted, and discuss the differences in the ways that the flagship species were used.

\section{Criteria for selecting 'locally appropriate' flagship species}

This list of 10 criteria indicates the range of factors that need to be examined when considering whether a particular species could be an effective flagship species at a local level:

\section{Geographical distribution}

To be effective in promoting local conservation the species must occur within the focal area and should be typical of locally important habitats. Species that are endemic or have a restricted distribution may provide a symbol of regional, ethnic or national allegiance, and thus reinforce the effectiveness of such species as flagships.

\section{Conservation status}

Although flagship species have traditionally been those with a high risk of extinction, species that are not threatened may still be suitable. A greater local awareness of common species, relative to infrequently encountered rare species, may make them effective local ambassadors for conservation (Entwistle \& Stephenson, 2000).

\section{Ecological role}

The benefits of using a flagship species can be increased by focusing on a species that has a central role in the ecosystem (in line with the umbrella species and keystone species concepts; Caro \& O'Doherty, 1999; Leader-Williams \& Dublin, 2000). Such species provide opportunities to explain to local communities the relationships between different species, and the value of seemingly unimportant species.

\section{Recognition}

The species or taxa should be known to the target audience, and should be distinctive and not readily confused with other species.

\section{Existing usage}

Species that are already in use as symbols by other organizations or products should only be used as flagship species if there is no potential conflict of messages, and if the focal audience can clearly distinguish these uses. However, repeated use of similar motifs by different organizations working towards compatible goals may reinforce conservation messages.

\section{Charisma}

Although flagship species have traditionally been charismatic large mammals or birds, charisma is a subjective assessment. The appeal of novelty and interest in less traditionally charismatic species should not be overlooked (Entwistle \& Dunstone, 2000). Such species can still effectively influence public opinion (Entwistle, 2000). In Bermuda the endemic skink Eumeces longirostris has provided an important focus for conservation of some of the island's remaining natural areas (BAMZ, 1997; A. Glasspool, pers. comm.), and a snake has been used as a focus for conservation in Antigua (Daltry et al., 2001). 


\section{Cultural significance}

Any cultural associations of the species should be identified, including relationships to folklore or art, or use for food or handicrafts. There may be opportunities to reinforce existing cultural associations with flagship species by using representations of the species based on local artwork and stylistic interpretations.

\section{Positive associations}

Species with positive associations for the focal audience are more likely to be effective. It should not be assumed that strong associations with a particular species are necessarily positive (e.g. the strong but negative reputation of the wolf in European folklore and traditions).

\section{Traditional knowledge}

The existence of traditional local knowledge of species is not only a valuable source of information to conservationists but also provides opportunities to build upon, and reinforce, a community's existing knowledge. For example, local communities in the northern Solomon islands are able to provide information on roost sites of fruit bats and can discriminate between commoner species (Bowen-Jones et al., 1997).

\section{Common names}

Only names whose local meanings or interpretations do not have negative connotations should be used. The common name of a species may influence public perception (Carvell, 1998), and a change of name can be used to improve the image of a species (e.g. the use of the term 'painted $\operatorname{dog}^{\prime}$ for African wild dog Lyacon pictus; G. Rasmussen, pers. comm.).

\section{Case studies}

With the notable exception of Dietz et al. (1994) there are few published examples of the application of the flagship species concept, particularly at a local level. The three case studies below are drawn from our own experience, and demonstrate how, using contrasting approaches, flagships have been introduced into projects in different cultural contexts. In Table 1 these flagship species are assessed against the 10 proposed criteria. The three projects demonstrate:

- the use of an internationally recognized flagship species, the Asian elephant, in a locally appropriate context in Indonesia, through a project implemented by Fauna \& Flora International (FFI);
- the use of a less traditionally charismatic, but locally appropriate, fruit bat species as a flagship species in an ongoing community conservation project managed by one of us (A.E.) on Pemba; and

- the identification of a non-threatened tree as a culturally significant local flagship species in Central America, where FFI is helping a local organization to establish a corridor reserve.

\section{Conservation of elephant landscapes in Aceh, Indonesia}

The need to promote the conservation of biodiversity outside the existing protected areas system is well recognised in Indonesia. To address the conservation issues affecting upland habitats in Aceh on Sumatra, a landscape-level project was developed using a culturally important symbol, the Asian elephant Elephas maximus. The use of this species provided opportunities to engage all stakeholders in the project and in associated conservation issues. Key stakeholders included local villagers, rural enterprises, regional decision makers and those involved in the national land planning system.

The potential of the elephant as a flagship species was assessed by an extended consultation process with local government and villagers in areas used by wild elephants (Plate 1). This consultation revealed the depth of traditions regarding elephants, based on historical, religious and cultural beliefs, and on a reverence for elephants that has only recently begun to decline (B. Suprayogi, unpub. data). In fact the Acehnese people still tolerate crop-raiding and injury from elephants, despite the obvious conflicts.

Elephants were used in a number of ways as part of the project. Captive elephants were ridden during conservation patrols around so-called 'protection forests' to help detect illegal logging activities, thus demonstrating the practical use of this species. The same elephants

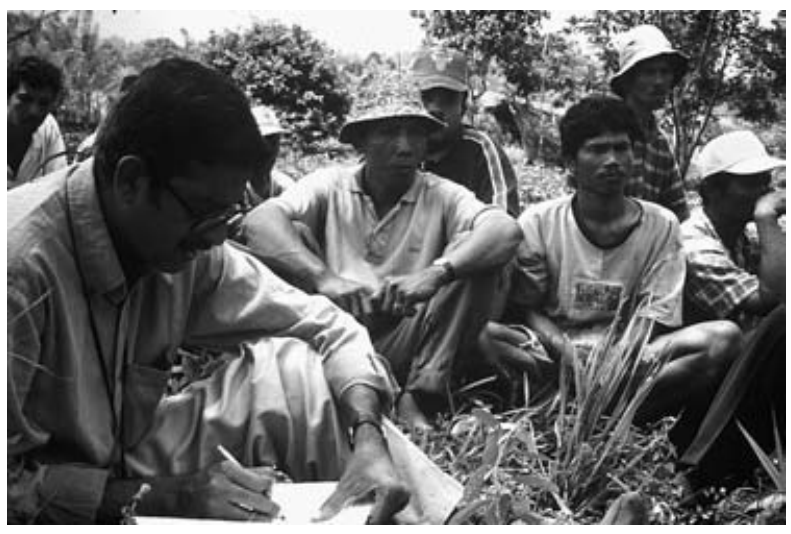

Plate 1 Community consultations being carried out in Aceh. Evan Bowen-Jones/FFI. 


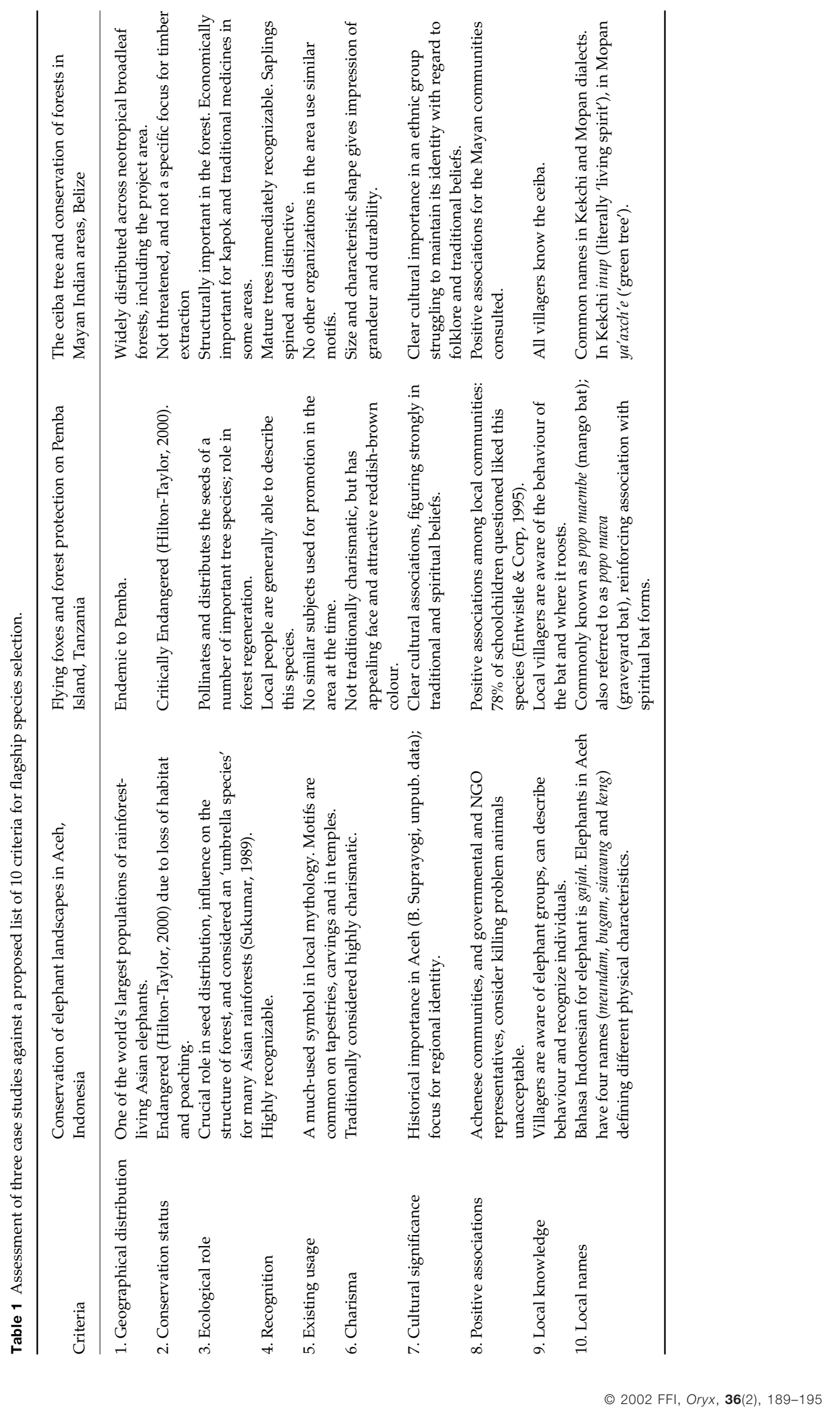


were used as part of awareness-raising initiatives in the villages that the patrols passed through. Additionally, mahouts used captive elephants to control crop-raiding wild elephants, and thus helped to reaffirm positive attitudes towards the species in communities that suffered crop-raiding or injuries from elephants. The cultural role of the species was reinforced using awareness materials based upon traditional Acehnese, as well as Western, depictions of elephants. In this project the elephant was a flagship species that was locally appropriate, surpassed racial divisions, and also appealed to Western and donor interest.

\section{Flying foxes and forest protection on Pemba Island, Tanzania}

The island of Pemba, c. $50 \mathrm{~km}$ off the shore of mainland Tanzania, supports relict primary forest and substantial areas of secondary clove forest, both under threat from habitat degradation and agriculture. The endemic Pemba flying fox Pteropus voeltzkowi was reportedly suffering population declines as a result of loss of habitat combined with heavy hunting pressure (Mickleburgh et al., 1992). This project was developed to increase local awareness of the threats facing this species and in the hope of developing local hunting regulations, whilst at the same time using the bat as a symbol for broader habitat conservation on the island (Entwistle \& Corp, 1997). The project focused on local communities and hunters living close to bat roosts, and school-aged children (Plate 2) who acted as ambassadors for the bats, and the project, within their communities.

Interviews with villagers and children revealed positive local attitudes to the bats, reflecting both a general perception of the species as well as the impacts of previous environmental education campaigns (Entwistle

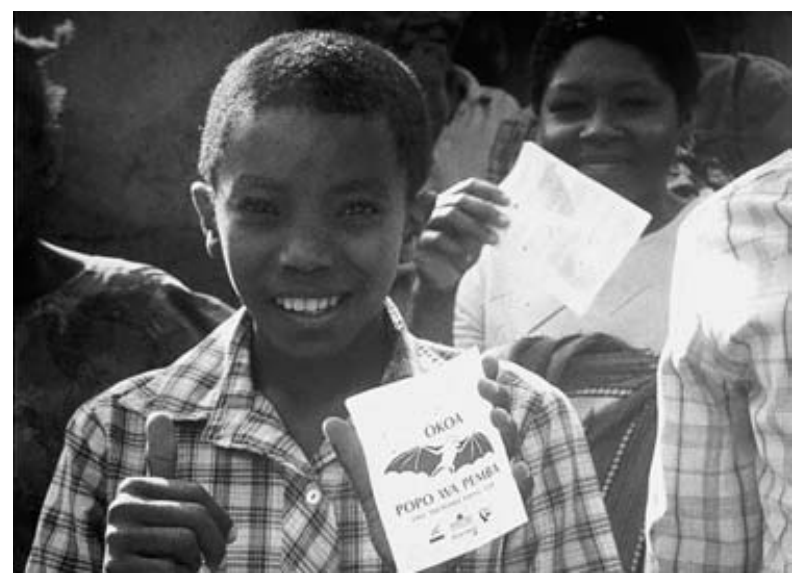

Plate 2 Pembari schoolboy holding education and awareness materials that employed a simple bat motif. Nadia Corp.
\& Corp, 1995). Villagers considered the Pemba flying fox important as a source of food, but also held it in cultural esteem because bats figure strongly in traditional beliefs and are associated with traditional graveyards and sacred sites. In addition, the endemic status of this species provided a focus for island-level pride, which reinforced the Pembaris' unique regional identity. On this basis, the species was considered relevant for use as a flagship for conservation initiatives beyond the protection of the species itself.

The flying foxes have remained a central focus for the project. A symbolic representation of a fruit bat was adopted as the project logo and used on leaflets, stickers and t-shirts. By looking at the relationship between fruit bats and forests, specifically forest regeneration, the bat has become an effective point of engagement to discuss conservation of natural habitats across the island with local stakeholders. The communities have developed a feeling of ownership for the project and instigated local controls on off-take of the species. They have also developed community-based protection mechanisms for a number of natural and semi-natural areas that are sanctuaries for this and other species.

In contrast to many parts of the world where bats are feared or persecuted (Mickleburgh et al., 1992), this example demonstrates that, when local contexts are considered, even species that are not typically considered charismatic can be successfully adopted as flagship species.

\section{Conservation of forests in Mayan Indian regions}

Today, as in the past, Mayan communities make up the majority of the inhabitants of the Toledo District of southern Belize. The Golden Stream Corridor Preserve aims to protect the forest and to enhance the quality of life for local communities around the Preserve, and thus to relieve pressure on the use of resources in the forest. As part of the development of this project, consultations were held with the Kekchi- and Mopan-speaking Mayan villagers living nearest to the Preserve, including community-led identification of appropriate flagship species.

Community consultations identified the ceiba (or kapok) tree Ceiba pentandra as a potential flagship species that possesses strong cultural links at a local level, as well as an important ecological role. The ceiba plays a central role in beliefs and folklore within Mayan communities. Traditional Mayan beliefs held that this tree, a rainforest emergent (Plate 3), connected the real world to the under or spirit world through its huge roots, and its upper branches were believed to act as a seat from which the gods watched the people walking below. Other stories associate the ceiba with the acquisition of material wealth and wisdom. 


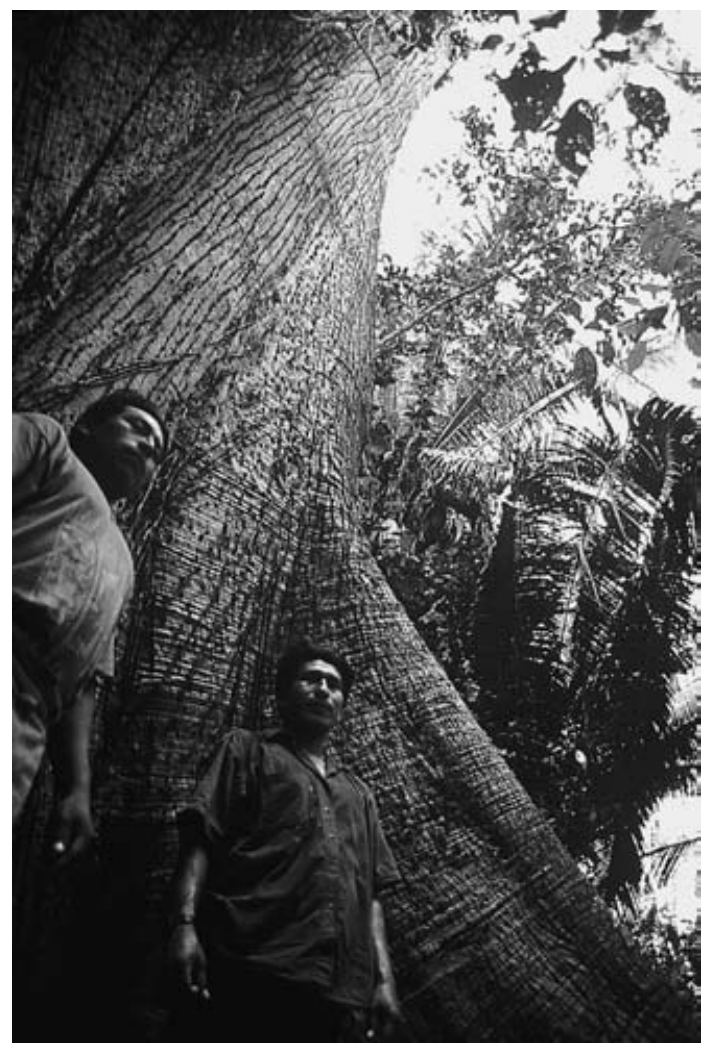

Plate 3 Mayan villagers standing beneath one of the largest ceiba trees in the Golden Stream Watershed, Toledo, Belize. Evan Bowen-Jones/FFI.

The local NGO managing the project recently changed its name to Ya'axche Conservation Trust, based on the local Mopan word for the ceiba. It has been proposed that a project logo be designed, based upon the ceiba, and that artwork be developed based on the traditional Mayan glyph for this tree, thus symbolising both the species and the ethnicity of the communities associated with the project. The cultural significance of the ceiba and its link to Mayan traditions may also add interest and distinctiveness to this project for an international audience.

The use of a non-threatened tree as a flagship species contrasts with the use of a traditionally charismatic flagship species such as the jaguar Panthera onca in projects elsewhere in Belize. The jaguar occurs within the project area, but local people hold mixed views about this species and have expressed their fear of large predators and of the risks to their livestock. This suggests that while large cats may have a role in eliciting international funding, the ceiba may offer a better tool to communicate the aims of the project, and the general goals of conservation, to the local residents.

\section{Conclusions}

Conservation organizations and projects have an important marketing tool at their disposal: the species they aim to protect. The symbolic appeal of animal species has been recognized, and has long been exploited in the promotion of a host of popular 'brand name' species. Species are also used as emblems for individual organizations. However, we feel that at the local level the marketing opportunities for conservation offered by the use of locally appropriate flagship species could be better exploited. Using consultation and research to establish local perceptions of individual species, there is potential to foster closer cultural ties to conservation projects.

The use of locally identified flagships would increase the range of species used to promote conservation. This may reduce potential 'flagship fatigue', whereby the impact of more traditional flagship species is reduced by over-exposure. As with any form of marketing, individual messages or symbols may have a limited 'shelf-life', and the use of flagship species that generate public interest through their novelty, unusual appearance or behaviour could broaden support for conservation.

The selection of flagship species based upon local as well as international criteria provides a tool to address an important challenge in biodiversity conservation worldwide. Locally appropriate flagship species, identified through research and consultation, could play a key role in encouraging a wider level of support and commitment from those who ultimately underlie the success of many conservation initiatives - local communities.

\section{Acknowledgements}

The Conservation of Elephant Landscapes in Aceh project was developed by Fauna \& Flora International for the Global Environmental Facility (operated through the World Bank). The work on the Pemba flying fox was funded by grants from the FFI 100\% Fund, the People's Trust for Endangered Species, and the Lubee Foundation. Golden Stream Corridor Preserve is run by Ya'axche Conservation Trust, with support from Fauna \& Flora International, and was purchased through the Arcadia Fund. We would like to thank all those who provided information and discussion on the three case studies presented, including Mike Appleton, Jose Pop and Bambang Suprayogi.

\section{References}

BAMZ (Bermuda Aquarium, Museum and Zoo) (1997) Bermuda Biodiversity project: Bermuda Skink Project. http://www.bamz.org/biodiversity/skink 
Borrini-Feyerabend, G. (ed) (1997) Beyond Fences: Seeking Social Sustainability in Conservation. IUCN, Gland, Switzerland.

Bowen-Jones, E., Abrutat, A., Markham, B. \& Bowe, S. (1997). Flying foxes on Choiseul (Solomon Islands) - the need for conservation action. Oryx, 31, 209-217.

Caro, T.M. \& O'Doherty, G. (1999) On the use of surrogate species in conservation biology. Conservation Biology, 13, 805-814.

Carvell, C. (1998) Choosing flagship species for conservation. MSc project, Imperial College of Science, Technology and Medicine. London.

Daltry, J.C., Bloxam, Q., Cooper, G., Day, M.L., Hartley, J., Henry, M., Lindsay, K. \& Smith B.E. (2001) Five years of conserving the 'world's rarest snake', the Antiguan racer Alsophis antiguae. Oryx, 35, 119-127.

Dietz, J.M., Dietz, L.A. \& Nagagata, E.Y. (1994) The effective use of flagship species for conservation of biodiversity: the example of lion tamarins in Brazil. In Creative Conservation: Interactive Management of Wild and Captive Animals (eds P.J.S. Olney, G.M. Mace \& A.T.C. Feistner), pp. 32-49. Chapman \& Hall, London.

Entwistle, A.C. (2000) Flagships for the future? Oryx, 34, 239-240.

Entwistle, A.C. \& Corp, N. (1995) Status and Conservation of the Pemba Flying Fox. Unpublished Report, University of Aberdeen/Fauna \& Flora International.

Entwistle, A.C. \& Corp N. (1997) Status and distribution of the Pemba flying fox Pteropus voeltzkoi. Oryx, 31, 135-142.

Entwistle, A.C. \& Dunstone, N. (2000) Future priorities for mammalian conservation. In Priorities for the Conservation of Mammalian Diversity. Has the Panda had its Day? (eds

A. Entwistle \& N. Dunstone), pp. 369-387. Cambridge University Press, Cambridge, UK.

Entwistle, A.C. \& Stephenson, P.J. (2000) Small mammals and the conservation agenda. In Priorities for the Conservation of Mammalian Diversity. Has the Panda had its Day? (eds A. Entwistle \& N. Dunstone), pp. 119-139. Cambridge University Press, Cambridge, UK.

Heywood, V.H. (ed.) (1995) Global Biodiversity Assessment. Cambridge University Press, Cambridge, UK.

Hilton-Taylor, C. (compiler) (2000) 2000 IUCN Red List of Threatened Species. IUCN, Gland, Switzerland and Cambridge, UK.
Hutton, J. \& Dickson, B. (2000) Endangered Species Threatened Convention. The Past, Present and Future of CITES. Earthscan, London, UK.

Knights, P., Watts, S., Paul, L. \& Enderson, B. (2000) Summary of the Shark Conference 2000, Honolulu, Hawaii. http:/ /www.westpacfisheries.net/sharkcon/summary

Leader-Williams, N. \& Dublin, H.T. (2000) Charismatic megafauna as 'flagship species'. In Priorities for the Conservation of Mammalian Diversity. Has the Panda had its Day? (eds. A. Entwistle \& N. Dunstone), pp. 53-81. Cambridge University Press, Cambridge, UK.

Mickleburgh, S.P., Hutson, A.M. \& Racey, P.A. (compilers) (1992) Old World Fruit Bats. An Action Plan for their Conservation. IUCN/SSC Chiroptera Specialist Group. IUCN, Gland, Switzerland.

Nowell, K. \& Jackson, P. (eds) (1996) Wild Cats Status Survey and Conservation Action Plan. IUCN/SSC Cat Specialist Group. IUCN, Gland, Switzerland.

Posey, D.A. \& OCEES (eds) (1999) Cultural and Spiritual Values of Biodiversity. UNEP/Intermediate Technology Publications, London.

Sukumar, R. (1989) The Asian Elephant Ecology and Management. Cambridge University Press, Cambridge, UK.

Werner D.I. (1991) The rational use of green iguanas. In Neotropical Wildlife Use and Conservation (eds J.G. Robinson \& K.H. Redford), pp.181-201. The University of Chicago Press, Chicago, USA.

\section{Biographical sketches}

Evan Bowen-Jones has worked at Fauna \& Flora International (FFI) for five years. He currently manages the FFI Bushmeat Programme and also acts as biodiversity specialist for the FFI Americas Programme. He has worked in West Africa, Central and South America, and the Asia Pacific region on a wide range of taxa and issues.

Dr Abigail Entwistle is the Senior Scientist for FFI. Her current work focuses on managerial and technical inputs to projects in the Caribbean and Eurasia. She has a strong interest in issues relating to mammalian conservation, with a particular focus on bats. 